\title{
ALIENAÇÃO E FETICHISMO: HÁ ALGO DE FEUERBACH NO "CAPITAL" DE MARX?
}

Alan Brandão de Morais ${ }^{1}$

RESUMO: Seguindo as sugestões de investigação conceitual dos textos de Karl Marx abertas pelo professor Celso Frederico no livro O Jovem Marx - As Origens da Ontologia do Ser Social, pretendemos com este texto elaborar uma pequena contribuição para o processo de recomposição conceitual das obras deste autor. A influência hegeliana e feuerbachiana da obra de Marx vem adquirindo novas faces na medida em que os comentadores contemporâneos dedicam-se a investigar as continuidades conceituais da sua formação filosófica de juventude na obra de maturidade, estabelecendo teses interessantes sobre a apropriação dialética feita por Marx de conceitos destes dois pensadores. Para cumprir este objetivo, nos concentraremos aqui na construção do conceito de fetichismo da mercadoria n' O Capital - Livro I, a partir de uma investigação profunda dos conceitos de Alienação em Feuerbach e Fetichismo em Marx, no sentido de estabelecer um campo conceitual que nos permita definir a possibilidade de estabelecer analogias, proximidades ou definir as distinções 
entre estes dois conceitos que, apenas aparentemente, guardam grandes semelhanças.

PALAVRAS-CHAVE: Materialismo, Individualidade, Gênero, Alienação.

ABSTRACT:_Following the suggestions of the conceptual investigation of Karl Marx's texts open by Celso Frederico in The Young Marx - origins of the Social Being Ontology, we pretend in this text to elaborate a little contribution to the process of conceptual recomposition of the works by this author. The hegelian and feuerbachian influence of the Marx works has acquired new features according as the dedication of contemporary commentators on investigate the conceptual continuities on his philosophical formation from the youth works to majority, establishing interesting thesis about the dialectical appropriation made by Marx of the concepts of these two authors. To fulfill this objective, we will concentrate on the formulation of the concept of merchandise fetishism at The Capital - Book 1, from an investigation of the concepts fo alienation in Feuerbach and fetishism in Marx on the way to establish a conceptual field capable of define the possibilities to generate analogies, proximities or to define the distinctions between these two concepts that, only apparently, hold great similarities.

KEYWORDS: Materialismo, Individuality, Genus, Alienation 
O Professor Celso Frederico, na introdução do livro "O Jovem Marx - As Origens da Ontologia do Ser social”, realiza uma pequena abordagem panorâmica dos diversos métodos pelos quais foram abordados os textos de Marx, principalmente aqueles elaborados na juventude, que expressam a sua formação filosófica. Entre o "silêncio constrangedor" das obras juvenis diante da conjuntura da revolução russa (Cf. FREDERICO, 2005, p.09), a polêmica desqualificação althusseriana $(2005, \mathrm{p} .10)$ e a redentora retomada destes textos por parte de existencialistas e marxistas contrários ao "marxismo soviético", a conhecida relação conceitual entre Hegel, Marx e Feuerbach, presente nos textos de juventude, segundo o autor, adquiriu contornos entre os comentadores marxistas que não alcança a força argumentativa própria daqueles textos. Eles demonstram, segundo Frederico, como Marx se apropria dialeticamente de conceitos destes autores para desenvolver teses originais e próprias. Segundo Celso Frederico, para além das celeumas teórico - políticas, estes textos

(...) conduzem a um emaranhado teórico composto de uma mescla de continuidade e ruptura com relação ao pensamento de Hegel e Feuerbach, bem como de tentativas do autor para desembaraçar-se dessas influências e propor o esboço de uma teoria 
nova e absolutamente original (FREDERICO, 2005, p.10).

Seguindo, portanto, esta sugestão, pretendemos neste texto investigar as complexas relações entre os conceitos de Alienação de Feuerbach e de Fetichismo da mercadoria, tratado no Livro I d'O Capital. Nosso objetivo aqui é investigar ambos os conceitos com o objetivo de expor as rupturas e continuidades entre eles e, desta forma, esclarecer como Marx engendra a construção do conceito de fetichismo da mercadoria a partir de aspetos conceituais compartilhados com a alienação religiosa feuerbachiana. Primeiramente, faremos o comentário de ambos os conceitos a partir da exegese dos textos originais - " $A$ Essência do Cristianismo" e "Princípios da filosofia do futuro" de Feuerbach e o já citado "O Capital - Livro 1" de Marx. Tendo como base este comentário de cada conceito, faremos a vinculação entre ambos, com vistas a adquirir subsídios satisfatórios para responder a questão título deste texto.

\section{ALIENAÇÃO EM FEUERBACH}

Etimologicamente, o termo alienação significa tornar algo alheio aquilo que, partindo de mim, passa a pertencer a 
um outro (SERRA, 2008, p.4). Em sentido estritamente filosófico, a alienação é utilizada para designar que a essência de um sujeito é firmada como algo externo, dominando-o pela sua superioridade com relação ao sujeito. Em Feuerbach, este sentido de alienação é largamente utilizado como modelo conceitual para sua crítica da teologia cristã e da filosofia especulativa, identificada justamente com a filosofia hegeliana.

Para Feuerbach, tanto a teologia cristã como a filosofia hegeliana promovem a alienação da essência humana, uma vez que projetam a essência do gênero humano para entidades conceitualmente abstratas ou sobrenaturais, respectivamente a Ideia absoluta e Deus ${ }^{2}$. Deste modo, "agem" impedindo que a humanidade conquiste plenamente a realização da sua liberdade. Por este motivo, o projeto de "desalienação" de Feuerbach transita pela crítica da teologia cristã e da filosofia especulativa, com vistas a demonstrar a impossibilidade de fundar racionalmente a natureza como ato de vontade da abstração - seja Deus ou a Ideia - para destacar o caráter originariamente sensível e gregário - antropológico - dos predicados absolutos legados ao divino ${ }^{3}$.

Seu projeto de desalienação por meio da filosofia tem início com a crítica da filosofia de Hegel (1843), haja vista que Feuerbach identifica o sistema hegeliano como uma variante da teologia cristã, uma vez que promove uma 
elaboração teorética de Deus, fundamentando filosoficamente a projeção das determinações humanas como abstratas determinações autônomas da Ideia.

Deus enquanto Deus - como ser espiritual ou abstracto, isto é, não humano, não sensível, acessível e objectivo só para a razão ou para a inteligência, nada mais é do que a essência da própria razão; mas esta é representada pela teologia comum ou pelo teísmo mediante a imaginação como um ser autónomo, diferente, distinto da razão. (FEUERBACH, 2008, p.09, \$06)

É importante analisarmos este trecho dos Princípios da Filosofia do futuro. Deus é a "essência da razão", um atributo humano, e que é considerado como um ser autônomo pela filosofia e pela teologia. Isso significa que Deus possui alguma relação com atributos humanos, mas, por algum motivo, ele se diferencia de nós, se aparta da sua origem para figurar como um mítico ser superior a reger os seres humanos com atributos inescapavelmente humanos. Deus não sintetiza apenas a essência da razão, mas também figura como vontade absoluta - uma vez que este Deus cria a natureza e toda a existência ex nihilo ${ }^{4}$ e como amor absoluto - representado principalmente pela paixão divina em sacrificar seu próprio filho pela expiação dos pecados 
humanos ${ }^{5}$. Vontade, amor e razão são, entretanto, como visto na Essência do Cristianismo ${ }^{6}$, atributos humanos que, ao serem considerados em sua infinitude, são legados a um ser superior.

A religião, pelo menos a cristã, é o relacionamento do homem consigo mesmo ou, mais corretamente: com sua essência; mas o relacionamento com a sua essência como uma outra essência. A essência divina não é nada mais do que a essência humana, ou melhor, a essência do homem abstraída das limitações do homem individual, i.e., real, corporal, objetivada, contemplada e adorada como uma outra essência própria. (FEUERBACH, 2007, p.45)

De fato, nenhum ser humano pode, isoladamente, querer, se apaixonar e pensar infinitamente. Somos seres naturais, finitos, imersos nas limitações da existência individual. Entretanto, a nossa limitação natural não nega o fato de que vontade, amor e razão são atributos originariamente humanos. Isso significa dizer que até mesmo a projeção infinita destes atributos, e a própria existência de Deus como suprema perfeição também deve emanar da existência humana, ou seja, é a partir da hipostasiação da nossa essência que se criam os deuses. Nesta premissa reside o segredo da virada antropológica da religião, uma vez que ao questionar a origem dos predicados 
infinitos de Deus, Feuerbach promove a reapropriação destes pela própria humanidade geradora destes predicados.

Esta reapropriação tem início com a crítica ao individualismo, caminho pelo qual Feuerbach conseguirá traçar seu projeto de "desalienar" a relação entre homem e Deus. Para Feuerbach, Deus adquire este atributo de ser a suprema perfeição na medida em que I) o indivíduo se coloca diante da sua grandeza e percebe a sua limitação perante a suprema perfeição, como abordado anteriormente, e II) Deus é o próprio arquétipo das infinitas possibilidades da vontade individual, tendo como principal exemplo a criação da natureza como um ato e vontade ${ }^{7}$. Contudo, esta ascensão do individualismo só se sustenta quando a humanidade é compreendida apenas pela razão pura, abstraída dessa compreensão a dimensão corporal do homem. A individualidade, como nos afirma Serrão (2009, p. 20), é a expressão social da perda da integridade do sujeito, "reduzido a uma alma", uma vez que o apreço pelo Deus transcendente - ou pela Ideia abstrata resultou em uma visão do indivíduo destituído de sensações e que, consequentemente, estabelece um contato precário com o mundo exterior, já que afirma a racionalidade ou a divindade como forças superiores à existência dos sensíveis.

A figura do eu esvaziado, destituído das sensações que o ligam ao aqui e agora da realidade mundana, 
acabaria por esfumar o mundo verdadeiro e tomar por verdade a volátil esfera das representações e das crenças. A aspiração da alma a prolongar-se indefinidamente no além, lugar de uma vida melhor após a morte, seria o derradeiro refúgio do individualismo e do egoísmo e, por consequência, a derradeira consumação do dualismo (SERRÃO, 2009, p.20).

Ao fornecer um sentido filosófico para a sensibilidade, Feuerbach pretende destacar a possibilidade de acessarmos a existência fora do pensamento, principalmente naquilo que concerne à relação entre indivíduos humanos. De fato, é na consciência que o ser humano possui de seu próprio gênero que reside a sua capacidade para tornar infinitas as suas próprias capacidades. Em nossa relação sensível com a natureza ${ }^{8}$, nós a objetivamos no intuito de satisfazer necessidades individuais dos nossos corpos, o que gera um nível específico de consciência, a saber, a consciência de si mesmo como indivíduo. Entretanto, o fato de que a humanidade desenvolve religião e ciência, em vinculação sensível com a natureza, nos indica que a consciência humana ultrapassa este nível de fenomênico de consciência. Somos capazes de compreender a nossa individualidade não apenas imersos em nós mesmos, mas também, como parte de uma vida exterior (natural) e como integrante a uma vida 
interior compartilhada com outros iguais. A esta segunda capacidade, Feuerbach dá o nome de consciência genérica.

De fato, é o animal objeto para si mesmo como indivíduo - por isso tem ele sentimento de si mesmo - mas não como gênero - por isso falta-lhe a consciência, cujo nome deriva de saber. Onde existe consciência (em sentido rigoroso) existe a faculdade para a ciência. A ciência é a consciência dos gêneros. Mas, somente um ser para o qual seu próprio gênero, a sua quididade torna-se objeto, pode ter por objeto outras coisas ou seres de acordo com a natureza essencial deles. (FEUERBACH, 2007, p.35).

É este caráter genérico, esta duplicidade própria do ser humano, que compõe a essência da teologia e da religião. Deus torna-se a resposta objetiva para a dificuldade que temos em aliar, na nossa consciência individual, a consciência do gênero e as limitações da individualidade, compreendendo aquilo que possuímos dentro de nós como algo objetivado, externo a nós ${ }^{9}$. No entanto, esta vida genérica pode ser facilmente apreendida quando comparados o predicado divino da onipresença com as realizações da humanidade em seu conjunto.

O que se passa com a omnisciência divina passa-se também com a omnipresença divina, que também se 
realizou no homem. Sim, enquanto o homem observa esta estrela do ponto de vista da Europa, observa simultaneamente a mesma estrela do ponto de vista da América. O que é absolutamente impossível a um homem só, é possível a dois. Mas Deus está ao mesmo tempo em todos, em todos os lugares, omnisciência ou omnipresença só existe na representação, na imaginação e, por conseguinte, não se deve passar por alto a importante distinção já várias vezes mencionada entre a coisa apenas imaginada e a coisa real. (FEUERBACH, 2008, p. 21).

Entretanto, imerso no individualismo, esta consciência permanece velada, distante daquele que efetivamente realiza aquelas capacidades supremas ${ }^{10}$. Deste modo, se conforma a alienação da essência humana em Deus para Feuerbach. Segundo ele, é na nossa incapacidade de reconhecer os atributos de Deus enquanto produto da nossa vivência imanente como coletividade que reside o alheamento da nossa essência para Deus ${ }^{11}$. O projeto de "desalienação" da humanidade, a sua "nova filosofia", portanto, é uma inversão da inversão, a partir de um resgate das características mais sensíveis tomadas como originárias, aquelas responsáveis por tornar a vinculação humana não apenas uma mistificação distante, teológica, mas uma verdade para a filosófica e anti-dogmática. 


\section{FETICHISMO DA MERCADORIA EM MARX}

Passemos agora à segunda parte deste escrito, analisando os elementos concernentes ao fetichismo da mercadoria. A palavra fetiche remete ao sentido usual de "feitiço", um objeto que aparentemente guarda poderes sobrenaturais de controle das ações daqueles com quem entra em contato (DUSSEL, 1986, p.103) ${ }^{12}$. Em Marx, este conceito é utilizado para designar a dimensão oculta do processo de troca de mercadorias, parte do conjunto da denúncia da sociabilidade burguesa empreendida por este autor a partir da análise pormenorizada da sua dimensão econômica e suas consequências sociais. À primeira vista, verificamos uma diferença entre a alienação feuerbachiana, de origem religiosa e humanista, com relação ao fetichismo marxiano, de caráter econômico e histórico-social. Entretanto, verificaremos que, apesar das diferenças, persiste algum fio de continuidade em ambos os projetos de inversão.

Para compreender o sentido do fetichismo, é necessário investigar aquilo que Marx considera como a "forma elementar da riqueza"13, a saber, a mercadoria. Comecemos então, abrindo nossos sentidos à própria palavra do autor sobre um conceito tão caro à sua crítica da economia política. 


\begin{abstract}
A mercadoria é, antes de mais nada, um objeto externo, uma coisa que, por suas propriedades, satisfaz necessidades humanas, seja qual for a natureza a origem delas, provenham do estômago ou da fantasia. (MARX, p.57, 2014)
\end{abstract}

A riqueza provém da mercadoria, pois, ela é um objeto útil - em sentido amplo - para qualquer sujeito e, consequentemente, detentora de valor, que se desdobra em valor de uso e valor de troca ${ }^{14}$. O valor de uso é sensivelmente e individualmente verificável, uma vez que corresponde à necessidade de cada mercadoria para cada detentor dela. Contudo, o valor a partir do qual trocamos mercadorias carrega um mistério não resolvido pela economia política clássica até então, uma vez que este designa um meio de igualação proporcional entre mercadorias sensivelmente diferentes cujo padrão de medida não compõe uma propriedade física das mercadorias, estando, portanto, livre do valor de uso ${ }^{15}$. Este valor de troca não é considerado em seu caráter útil ${ }^{16}$, mas sim, em seu caráter abstrato, ou seja, no tempo de trabalho socialmente necessário para a formação de qualquer mercadoria.

Cada uma dessas forças de trabalho se equipara às demais, na medida em que possua o caráter de uma força média de trabalho social e atue como essa força 
média, precisando, portanto, apenas do tempo de trabalho socialmente necessário para a produção de uma mercadoria. Tempo de trabalho socialmente necessário é o tempo de trabalho requerido para produzir-se um valor de uso qualquer, nas condições de produção socialmente normais, existentes e com o grau social médio de destreza e intensidade do trabalho. (MARX, 2014, p.61).

Portanto, o trabalho social determina o uso de um padrão de troca entre todas as mercadorias, baseada na dimensão extrassensorial do trabalho que, abstraído de seu caráter útil, singular e individual, entra na esfera social a partir de um critério exterior à sua própria atividade. Todavia, com a intensificação da troca de mercadorias, o trabalho social não é suficientemente eficaz para padronizar a troca das mercadorias, uma vez que este valor, sendo de troca, se define na equivalência entre duas mercadorias e não isoladamente ${ }^{17}$, sendo, portanto impossível definir aprioristicamente, no circuito comercial, o valor de cada mercadoria a não ser que exista um equivalente geral aos quais todas as outras mercadorias se remetam para definir seu valor ${ }^{18}$. Esta mercadoria, alçada ao caráter de equivalente geral das outras mercadorias, cumpre o papel de ser pura expressão de valor mercantil, abstraindo-se, desta forma, de seu caráter utilitário ${ }^{19}$. O dinheiro é a 
consequência histórica desta determinação da mercadoria, uma vez que o desgaste físico da mercadoria transformada em equivalente geral torna necessário o uso de "títulos promissórios" que garantam a integridade física do equivalente geral. A estes títulos damos o nome de moeda.

Com o equivalente geral e o dinheiro alcançamos o ápice da mistificação da economia política burguesa. Com o advento histórico do equivalente geral, uma das mercadorias adquire o atributo de ser $\mathrm{o}$ representante de valor, sendo ela, e não a duplicidade própria das mercadorias, a origem da riqueza, o que gera, com a intensificação da troca entre mercadorias, uma consciência invertida de que é o equivalente geral, e não o trabalho humano que produz as mercadorias, a origem da riqueza. Um "simples expediente utilizado para resolver coisas práticas" transforma-se no sentido ordenador do processo de troca de mercadorias e, como Marx bem apresentará no restante d'O Capital, ordenador da própria sociabilidade burguesa.

A igualdade dos trabalhos humanos fica disfarçada sob a forma da igualdade dos produtos do trabalho como valores; a medida, por meio da duração, do dispêndio de força humana do trabalho; finalmente, as relações entre os produtores, nas quais se afirma o caráter social dos seus trabalhos, assumem a forma 
de relação social entre os produtos do trabalho (MARX, p.93, 2014).

A própria mercadoria, como vimos, carrega este, até então, misterioso atributo do valor de troca. Quando considerada, não isoladamente, mas inserida no circuito de trocas comerciais, aquilo que é originário do dispêndio humano de energia corporal torna-se um produto autônomo com valor e circulação próprios, ocultando, assim aquele trabalho útil que gerou esta mercadoria e esta riqueza em primeiro lugar. A elevação do equivalente geral corporifica esta ocultação uma vez que o valor se torna um atributo impregnado nas mercadorias, embora não seja possível verificar um átomo de valor de troca em sua constituição material.

Esta ocultação adquire poder autônomo em uma sociabilidade fundada na troca incessante de mercadorias. $\mathrm{O}$ dinheiro permite ao proprietário do equivalente geral acessar a totalidade da produção humana, o que garante ao dinheiro um poder que transcende as limitações da existência humana. Se realizo trabalho útil, possuo uma mercadoria. Mas se tenho dinheiro, então posso adquirir uma infinidade de mercadorias. Contudo, a igualação completa dos produtos do trabalho humano só se efetiva quando abstraímos destas mercadorias seu caráter singular, ou seja, o efetivo dispêndio de força humana dedicado para 
a produção de cada mercadoria. $\mathrm{Na}$ asseveração da troca das mercadorias, paradoxalmente, esta característica crucial para a produção das mercadorias, e consequentemente, o caráter social do valor e da consolidação da forma dinheiro, se velam diante da autonomização mística do dinheiro enquanto corporificação do valor.

Para encontrar um símile, temos de recorrer à região nebulosa da crença. Aí, os produtos do cérebro humano parecem dotados de vida própria, figuras autônomas que mantêm relações entre si e com os seres humanos. É o que ocorre com os produtos da mão humana, no mundo das mercadorias. Chamo a isso de fetichismo, que está sempre grudado aos produtos do trabalho, quando são gerados como mercadorias. É inseparável das mercadorias. (MARX, 2014, p.94)

O fetichismo é, portanto, uma resultante da asseveração histórica das trocas de mercadorias, possível apenas com o advento da revolução industrial, que transferiu características da alienação religiosa, no seu sentido feuerbachiano, para o campo da economia, tendo o dinheiro como figura central ${ }^{20}$. Essa asseveração projeta no dinheiro aquilo que foi produzido pela razão ou trabalho humano para simplificar a troca de mercadorias, a saber, a definição de um equivalente geral como depositário de 
trabalho abstrato que, ao ser retirado do circuito das mercadorias, define $o$ valor de todas as outras na equivalência própria da troca de mercadorias. A existência do dinheiro, portanto, consolida uma das principais características da alienação que é o velamento do trabalho humano que fornece valor ao dinheiro e às mercadorias, ou seja, o papel que a coletividade social cumpre na formação destas hipostasiações econômicas.

Em outras palavras, os trabalhos privados atuam como parte componentes do conjunto do trabalho social, apenas através das relações que a troca estabelece entre os produtos do trabalho e, por meio destes, entre os produtores. Por isso, para os últimos, as relações sociais entre seus trabalhos privados aparecem de acordo com o que realmente são, como relações materiais entre pessoas e relações sociais entre coisas, e não como relações sociais diretas entre indivíduos em seus trabalhos. (MARX, p.95, 2014).

A solução para o fetichismo da mercadoria reside não apenas no conhecimento do fetichismo, uma vez que, estando plenamente estabelecida esta prática econômica, não há diferença entre saber ou não da origem humana do valor já que "interessa aos que trocam produtos o quanto da outra mercadoria podem receber pela sua" (MARX, p.96, 
2014). A superação do fetichismo da mercadoria pressupõe uma intervenção de ordem prática no mundo das mercadorias de modo a evidenciar o caráter social do trabalho humano a partir de uma racionalização ampla da produção econômica, o que Marx sugere na sua rápida alusão a uma possível "sociedade de homens livres" que, em contraponto ao individualismo da sociabilidade burguesa baseada na troca de mercadorias ${ }^{21}$ defendidas pela economia política clássica, destaca a complexidade do trabalho social em todas as suas facetas e, deste modo, desmistifica o dinheiro como detentor do valor, apresentando-o como resultado do trabalho humano social.

Reproduzem-se aqui todas as características do trabalho de Robinson, com uma diferença: passam a ser sociais, ao invés de individuais. Todos os produtos de Robinson procediam de seu trabalho pessoal, exclusivo e, por isso, eram, para ele, objetos diretamente úteis. Em nossa associação, o produto total é um produto social. Uma parte desse produto é utilizada como novo meio de produção. Continua sendo social. A outra parte é consumida pelos membros da comunidade. Tem, portanto, de ser distribuída entre eles. (MARX, 2014, p.100)

A consequência, portanto, da "associação dos homens livres" é a evidência de que todo produto é resultado de um 
trabalho humano social e não individual, e que todo valor é proveniente de um dispêndio de trabalho humano individual inserido em uma coletividade. Este exercício de pensamento, uma das poucas alusões de Marx ao formato de uma sociedade futura, nos leva a confrontar a sociedade fetichizada com a sua realidade encoberta pela existência do dinheiro. Esta adquire, em face daquela, ares fortemente religiosos, já que em sua prática projeta a atividade humana social para o dinheiro ou equivalente geral. A forma de superar este fetichismo pressupõe, não obstante, uma atividade prática de inversão do mundo das mercadorias.

O reflexo religioso do mundo real só pode desaparecer quando as condições práticas das atividades cotidianas do homem representem, normalmente, relações racionais claras entre os homens e entre estes e a natureza. (MARX, 2014, p.101)

Desta forma, e encaminhando-nos para a conclusão, é possível verificar que existe muito de Feuerbach em Marx, no que tange à relação entre os conceitos de alienação e fetichismo. Apesar das respectivas críticas centrarem-se em objetos diferentes - religião e economia - ambas se assemelham naquilo que configura a crítica dos limites do Esclarecimento, a saber, a impossibilidade deste - apesar 
dos anseios - de superar a religiosidade da sua filosofia e dos modos práticos de vida e, principalmente, a crença nos poderes infinitos do individualismo.

Tanto em Feuerbach, quanto em Marx, este aspecto da crítica ao Esclarecimento é uma constante, principalmente quando ambos os autores se debruçam sobre o tema da defesa do individualismo como princípio da liberdade. Enquanto em Feuerbach é no individualismo que reside a alienação dos predicados humanos, em Marx é no individualismo das relações mercantis de troca que reside o velamento do trabalho efetivamente social que gera valor, concentrado no dinheiro. Em ambos os casos, somente a religião - seja a cristã, a especulativa ou a do dinheiro - consegue manter, na mente das pessoas, a farsa do individualismo intacta diante das evidências de sua insuficiência.

No projeto de superação do individualismo, entretanto, reside uma importante diferença entre ambos. Enquanto Feuerbach acredita que a reapropriação racional sensível da vontade, razão e amor pela coletividade humana possibilita atingir imediatamente a consciência genérica, Marx propõe uma intervenção prática na sociabilidade que fundamenta o fetichismo, uma vez que não basta conhecer a racionalidade da alienação mercadológica; é necessário livrar-se dos condicionantes práticos que deram origem a este fetichismo e construir, também no mundo real, uma 
racionalização da troca de produtos que evidencie o caráter social da produção de mercadorias.

\section{NOTA}

1 Mestrando em Filosofia pela Universidade Federal da Bahia e pesquisador bolsista pela FAPESB. E-mail: alan.filos@gmail.com.

2 "Assim como a essência divina nada mais é do que a essência do homem, libertada dos limites da natureza, assim a essência do idealismo absoluto nada mais é do que a essência do idealismo subjectivo, liberta dos limites e, decerto, racionais, da subjectividade, isto é, da sensibilidade ou da objectalidade em geral." (FEUERBACH, 2008, p. 37, \$22)

${ }^{3}$ CF. FEUERBACH, p. 08, 2008, $\$ 02$

4 "O teísmo pensa para si Deus como a causa, mas como uma causa viva, pessoal, como o criador do mundo: Deus produziu o mundo pela sua vontade. Mas a vontade não basta. Onde existe a vontade deve também existir o entendimento: aquilo que se quer é apenas mester do entendimento. (FEUERBACH, 2008.” p.23, \$14)

${ }^{5}$ Cf. FEUERBACH, 2007, p. 77

6 "Mas então qual é a essência do homem, da qual ele é consciente ou o que realiza o gênero, a própria humanidade do homem? A razão, a vontade e o coração. Um homem completo possui a força do pensamento a força da vontade e a força do coração. A força do pensamento é a luz do conhecimento, a força da vontade é a energia do caráter, a força do coração é o amor" (FEUERBACH, p. 36, 2007). 
7 Esta segunda maneira de compreender a relação entre Deus e a consciência da individualidade se refere de forma mais precisa à reconstrução protestante da perfeição divina, centrada na figura de Jesus promovendo uma primeira "antropologização" da religião como é possível perceber a seguir: "O Deus que é o homem, portanto o Deus humano, isto é, Cristo - é apenas o Deus do Protestantismo. O Protestantismo já não se preocupa, como o Catolicismo, com o que Deus é em si mesmo, mas apenas com o que Ele é para o homem; por isso, já não tem como aquele nenhuma tendência especulativa ou contemplativa; já não é teologia - é essencialmente só cristologia, isto é, antropologia religiosa.” (FEUERBACH, p.08, 2008, \$2)

${ }^{8} \mathrm{O}$ enaltecimento da natureza em Feuerbach cumpre um importante papel ao materializar completamente, sem tornar uma essência dominadora, a dimensão originária de onde pode se erigir uma filosofia - É a partir da natureza que os homens produzem objetivações, necessárias primeiramente para a sobrevivência tornando-se, posteriormente, os conceitos abstratos largamente utilizados. Daí se deriva que o abstrato é efeito, e não causa, do sensível, natural uma vez que do nada, nada surge sendo necessária uma base material para a formação dos conceitos abstratos, como afirma CHAGAS: "A natureza não pode ter sido deduzida do espírito, já que ela possui uma qualidade completamente diferente dele; mas o espírito pode ser deduzido dela e esclarecido por ela, uma vez que o homem, como criação da natureza, é a identidade de todas as oposições, isto é, a unidade do espiritual com o natural.” (2009, p.39)

"“O objeto do homem nada mais é do que sua essência objetivada nada mais é que a sua própria essência objetivada. Como o homem pensar, como for intencionado, assim é o seu Deus: quanto valor tem o homem, tanto valor e não mais tem o seu Deus." (FEUERBACH, p.44, 2007) 10 "Segundo ele, o fato de o homem ter consciência de sua própria espécie, do seu ser genérico, faz dele um ser especial e distinto dos 
animais. Mas, ao defrontar-se com as características pertencentes ao seu gênero, nem sempre é consciente disto.” (SCHULZ, p.15, 2001)

11 "Que mais se pretende ainda? Temos, pois, aqui um exemplo concreto da verdade de que a representação humana de Deus é a representação que um indivíduo humano para si faz do seu género, de que Deus, enquanto totalidade de todas as realidades ou perfeições, nada mais é do que a totalidade sinopticamente compendiada para uso do indivíduo limitado, das propriedades do género repartidas entre os homens e que se realizam no decurso da história mundial."(FEUERBACH, 2008, p. 20)

${ }^{12}$ Fetiche vem do português "feitiço" (da raiz latina facere, fazer, é o fato igualmente, de onde deriva igualmente feitiço) e significa o feito pela mão dos homens, mas que pretende aparecer como divino, absoluto, digno de culto; fascinante, tremendo, diante do qual se treme de espanto, terror, admiração.

${ }^{13}$ Riqueza que é o objeto conceitual fundante da tradição da Economia Política, que teve como precursores Ricardo, Say, Adam Smith e como um dos seus principais detratores, o próprio Marx na obra em questão. O objetivo desta ciência é a compreensão de como a riqueza surge e quais leis regem a sua circulação na sociedade moderna.

${ }^{14}$ Cf. MARX, p.58, 2014.

${ }^{15}$ Essa coisa comum não pode ser uma propriedade das mercadorias, geométrica, física, química, ou de qualquer outra natureza. As propriedades materiais só interessam pela utilidade que dão às mercadorias, por fazerem destas valores de uso. Põem-se de lado os valores de uso das mercadorias quando se trata da relação de troca entre elas.

${ }^{16}$ Sensível e relacionado com a diferença específica do trabalho para formar cada mercadoria diferente. (Cf. MARX, p.60, 2014)

17 "A forma relativa e a forma equivalente se pertencem uma à outra, se determinam reciprocamente, inseparáveis, mas ao mesmo tempo, são 
extremos que mutuamente se excluem e se opõem, polos da mesma expressão de valor.” (MARX, p.70, 2014).

18 "A forma geral do valor, ao contrário, surge como obra comum do mundo das mercadorias. O valor de uma mercadoria só adquire expressão geral porque todas as outras mercadorias exprimem seu valor através do mesmo equivalente, e toda nova espécie de mercadoria tem de fazer o mesmo." (MARX, p.88, 2014)

19 "O corpo da mercadoria que serve de equivalente passa sempre por encarnação do trabalho humano abstrato e é sempre o produto de um determinado trabalho útil, concreto. Esse trabalho concreto torna-se, portanto, expressão de trabalho humano abstrato.” (MARX, p. 80, 2014) 20 "É, porém, esta forma acabada do mundo das mercadorias, a forma dinheiro, que realmente dissimula o caráter social dos trabalhos privados e, em consequência, as relações sociais entre os produtores particulares, ao invés de pô-las em evidência.” (MARX, p. 97, 2014).

${ }^{21}$ Neste ponto, Marx faz alusão ao personagem da literatura inglesa Robinson Crusoé que, ilhado devido à um naufrágio, realiza, ordenadamente e sozinho, todas as atividades necessárias a sua sobrevivência. Com esta figura, Marx ilustra o absurdo da economia política clássica e da sociedade burguesa, a saber, que o indivíduo pode ser considerado o responsável pela produção efetiva de toda riqueza que possui (Cf. MARX, p.98, 2014). 


\section{REFERÊNCIAS BIBLIOGRÁFICAS}

DUSSEL, Enrique. Filosofia da Libertação na América Latina. Edições Loyola, São Paulo - SP, 1986.

FEUERBACH, Ludwig. Princípios da Filosofia do Futuro. Editora Lusofia Press, Covilhã - PT, 2008.

- Para a Crítica da Filosofia de Hegel.

Editora Liberars, São Paulo - SP, 2012.

FREDERICO, Celso. O Jovem Marx: 1843-1844: As Origens da Ontologia do Ser Social. Editora Expressão Popular, São Paulo-SP, 2009.

HEGEL, G.W.F. Filosofia do Direito. Editora Unisinos, São Leopoldo - RS, 2009.

MARX, Karl. Crítica da Filosofia do Direito de Hegel. Editora Boitempo, São Paulo, 2013.

MARX, Karl. O Capital: Livro I Editora Civilização Brasileira, Rio de Janeiro, 2014.

MOURA, Mauro C. B. Os Mercadores, do templo e a Filosofia: Marx e a religiosidade. EDIPUC-RS, Porto Alegre - RS, 2004.

SAMPAIO, Benedicto. Arthur. FREDERICO, Celso. Dialética e Materialismo: Marx entre Hegel e Feuerbach. Editora UFRJ, Rio de Janeiro - RJ, 2006. 
ALIENAÇÃO E FETICHISMO: HÁ ALGO DE FEUERBACH NO “CAPITAL” DE MARX?

SERRÃO, Adriana V. Feuerbach e a Apoteose da vida IN CHAGAS, Eduardo (Org.). Homem e Natureza em Ludwig Feuerbach. Edições UFC, Fortaleza - CE, 2009.

SCHULZ, Rosalvo. Religião e Capitalismo: Uma reflexão a partir de Marx e Feuerbach. Editoria PUCRS, Coleção Filosofia 126, Porto Alegre - RS, 2001. 